\title{
Pattern of body mass index, chronic diseases, and physical component of quality of life in a population in North of Iran: A latent class analysis
}

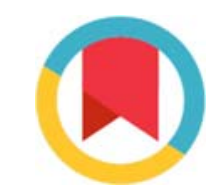

\author{
Ali Gholami ${ }^{1}$, Farhad Zamani ${ }^{2}$, Elham Zandian ${ }^{3}$, Masoudreza Sohrabi ${ }^{2}$, Farhad Moradpour ${ }^{4}$, Mansooreh Maadi², \\ Maryam Khazaee-Pool ${ }^{5}$, Abbas Abbasi-Ghahramanloo*6,7
}

Received: 27 Nov 2017

Published: 7 Nov 2018

\section{Abstract}

Background: Due to the rise of non-communicable diseases (NCDs) and lifestyle changes, this study aimed at determining the subclasses of Iranian adults based on body mass index, some NCDs, and status of physical component of quality of life.

Methods: A total of 5207 participants of Amol cohort study were studied in this study. Latent class analysis (LCA) was used to determine the best model with the minimum AIC or BIC.

Results: We decided that the 6 latent classes model was the best model. The first class described $35.1 \%$ of the participants and was characterized by individuals with no disease status. The sixth class described $0.7 \%$ of the individuals and was characterized by individuals exhibiting high probability of body mass index (BMI) equal or more than 25, kidney inadequacy, hypertension, and moderate physical component of quality of life status.

Conclusion: This study showed the pattern of body mass index, chronic diseases, and physical component of quality of life. Our findings demonstrated that some risk factors and non-communicable diseases tend to accumulate in some classes, especially classes 5 and 6 , and thus the risk of developing these diseases rises along with increase in their clustering abilities. These results point out the critical importance of designing specific preventive interventional programs for these stratums of individuals.

Keywords: Non-communicable diseases, Body mass index, Quality of life, Latent class analysis, Amol

Conflicts of Interest: None declared

Funding: None

*This work has been published under CC BY-NC-SA 1.0 license.

Copyright $₫$ Iran University of Medical Sciences

Cite this article as: Gholami A, Zamani F, Zandian E, Sohrabi M, Moradpour F, Maadi M, Khazaee-Pool M, Abbasi-Ghahramanloo A. Pattern of body mass index, chronic diseases, and physical component of quality of life in a population in North of Iran: A latent class analysis. Med J Islam Repub Iran. 2018 (7 Nov);32:109. https://doi.org/10.14196/mjiri.32.109

\section{Introduction}

Along with the third phase of the epidemiological transition towards the deep-seated disease, which is characterized by a decline in the mortality rate in combination with population aging, multimorbidity and co-occurrence of 2 or more chronic disorders has become more prevalent

Corresponding author: Dr Abbas Abbasi-Ghahramanloo, abbasi.abbas49@yahoo.com

1. Department of Public Health, School of Public Health, Neyshabur University of Medical Sciences, Neyshabur, Iran

2. Gastrointestinal \& Liver Disease Research Center (GILDRC), Firoozgar Hospital, Iran University of Medical Sciences, Tehran, Iran

3. Non-Communicable Diseases Research Center, Endocrine and Metabolic Research Institute, Tehran University of Medical Sciences, Tehran, Iran

4. Social Determinants of Health Research Center, Kurdistan University of Medical Sciences, Sanandaj, Iran

5. Department of Health Education and Promotion, School of Health, Zanjan University of Medical Sciences, Zanjan, Iran

6. Health Management Research Center, Baqiyatallah University of Medical Sciences, Tehran, Iran

7. Department of Epidemiology, School of Public Health, Iran University of Medical Sciences, Tehran, Iran worldwide (1).

Comorbidity is a concept that was originally developed by Feinstein as an additional clinical condition and refers to any additional co existing ailment that can be added to the preexisted chronic disease under study (2). Unlike

$\uparrow$ What is "already known" in this topic:

Gaining knowledge on multi-morbidity patterns of chronic conditions can help improve quality of life, reduce disability, and increase life expectancy. However, these types of patterns have been less studied in Iran.

\section{$\rightarrow$ What this article adds:}

Body mass index, chronic diseases, and physical component of quality of life have a pattern in surveyed study population. 
comorbidity, multimorbidity has no index condition and is associated with an increase in health care demand and a decrease in quality of life (3).

Some of the adult population are involved with the concurrent presence of more than 1 chronic disease, and this phenomenon is called multimorbidity (4). In the patient level, multimorbidity is related to higher mortality (5), weaker functional status, and lower quality of life (6).

Prevalence of multimorbidity varies with sex, age, ethnicity, and socioeconomic status (7-9). According to a recent systematic review, prevalence of multimorbidity ranged from $13 \%$ to $83 \%$. The prevalence rates were lower for studies that included less than 10 chronic disorders and were higher in studies that included a greater proportion in the population of older than 75 years. In general, the prevalence rate was greater than $60 \%$ worldwide and even much greater among those older than 85 years (10). Multiple chronic conditions can act cumulatively and interact with each other to adversely affect individual health prognosis, public health burden, and cost of treatment. Adding of 1 specific disorder to the pre-existed comorbidity of some chronic diseases can broadly affect healthrelated quality of life (11-14).

Determining the co-occurrence pattern of various chronic diseases is important because this information leads to identifying their common risk factors. For instance, if 2 disorders fall in the same category, they may have a common etiology (15). Having knowledge of the multi-morbidity patterns of chronic condition can also help improve quality of life, reduce disability, and increase life expectancy $(16,17)$.

It is easier for health care authorities to reduce the burden of such diseases that fall in the same clusters. Apparently, by knowing these classes, the patients will also be receiving a better service based on respective categories $(18,19)$. The objectives of this study were to investigate the clustering of 5 self-reported diseases (kidney inadequacy, hypertension, diabetes, metabolic syndrome, and digestive disorders) and find how these diseases are grouped with body mass index (BMI) and physical components of quality of life in the studied population of
Amol cohort study.

\section{Methods}

\section{Design, sample, and setting}

This study was performed within the framework of Amol (a city in the north of Iran) cohort study whose first phase started in 2008. Gastrointestinal and Liver Disease Research Center (GILDC) in Firoozgar hospital (Tehran) was the designer and possessor of the study. A total of 7104 individuals were selected in Amol cohort study using cluster random sampling from health care centers of Amol. All questionnaires were completed by interviewing each participant in Amol cohort study. In the present study, of all the population at baseline, 1897 individuals were excluded and data of 5207 participants were used (Fig. 1).

In this study, 6 dichotomous variables and 1 categorical variable were used to assess pattern of body mass index, chronic diseases, and physical component of quality of life. The variables were as follow: (a) kidney inadequacy (yes, no); (b) hypertension (yes, no); (c) diabetes (yes, no); (d) metabolic syndrome (yes, no); (e) digestive disorders; (f) BMI $\geq 25$ (yes, no); and (g) physical components of quality of life (poor, moderate, good).

\section{Diseases detection}

Any person who had already been diagnosed as having hypertension, diabetes, kidney inadequacy, digestive disorders, and metabolic syndrome by a physician or had used any medications related to these diseases at the time of the study was considered as a case.

\section{Physical components of quality of life}

This type of data was collected using the Iranian version of SF-12 questionnaire (11). The Short Form-12 Health Survey is a multidimensional questionnaire of healthrelated quality of life. This questionnaire includes 12 items and 8 health-related quality of life (HRQOL) scales, 4 of which (physical functioning, role-physical, bodily pain, general health) construct physical component sum-

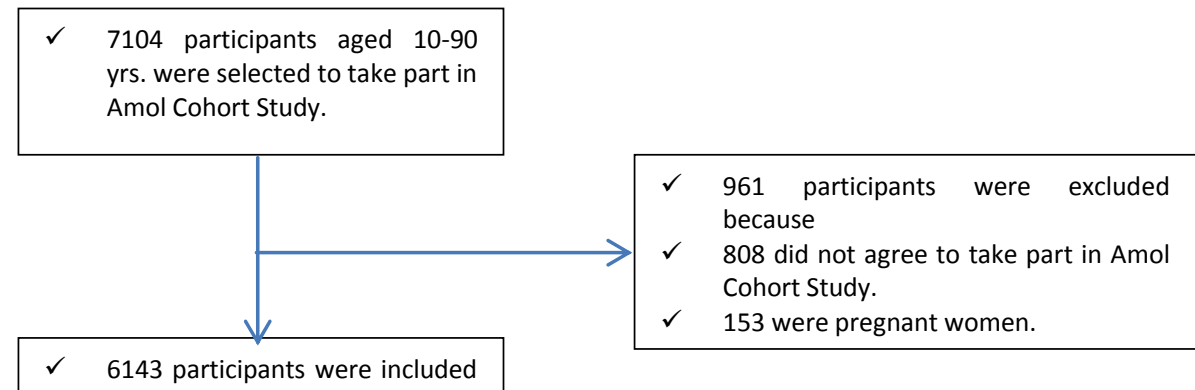

in Amol Cohort Study.

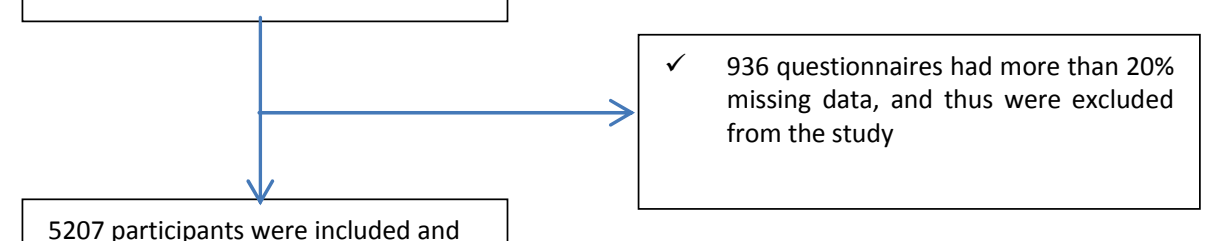

5207 participants were included and

analvzed in the present studv.

Fig. 1. Schematic diagram of study population selection 
mary (PCS). According to quartiles, scores equal and less than 40,41 and 80 , and $>80$ were considered as poor, moderate, and good physical health, respectively.

\section{Statistical analysis}

In this study, we implemented LCA for data analysis. This method is a latent categorical variable's model and traditionally classifies individuals with similar characteristics. Considering measurement error, this analysis assumes that the relationship of inter observed variables could be identifiable with latent variable.

In the first step, we calculated the $\mathrm{G}^{2}$ index, which is an index similar to $\mathrm{Chi}^{2}$. This was done using various iterations for the number of detected latent classes and comparing the number of observed response patterns with the expected ones. For the best comparison in model selection, we calculated Akaik information criterion (AIC) and Bayesian information criterion (BIC) based on G2 statistic. For all these indices, a smaller value indicated a better fit and parsimony for the model.

A total of 7 binary variables were used to detect the pattern of body mass index, chronic diseases, and physical component of quality of life.

Analyses were performed using PROC LCA in SAS 9.2 software (SAS institute Inc. Cary, NC, USA).

\section{Results}

Prevalence of BMI ( $\geq 25)$, kidney inadequacy, hyperten- sion, diabetes, metabolic syndrome, digestive disorders, and the status of physical component of quality of life in the study population are presented in Table 1 . This table indicates that the prevalence of some of the items is higher than others. For example, prevalence of BMI $(\geq 25)$ was $66.2 \%$. Also, this table shows that almost $52 \%$ of the participants were classified as having good level of physical components of quality if life.

We tried to fit LCA model with 1 to 10 classes. For each LCA model, $\mathrm{G}^{2}$, AIC, and BIC were computed and are demonstrated in Table 2. Considering the LCA model selection criteria and interpretability of the results, 6 latent classes model seemed to be appropriate.

Table 3 presents description of latent classes. The first row of this table shows the probability of belonging to each latent class, and the second part presents the probability of responses to questions about BMI, chronic diseases, and physical components of quality of life. These probabilities serve as the foundation for labeling and describing each of the 6 classes obtained by LCA method. Probabilities above 0.5 are bold to highlight the overall pattern. The first class described $35.1 \%$ of the participants and was characterized by individuals exhibiting no chronic disease status. The sixth class described $0.7 \%$ of the individuals and was characterized by individuals exhibiting high probability of BMI $(\geq 25)$, kidney inadequacy, hypertension, and moderate physical components of quality of life status.

Table 1. Percentages of demographic characteristics and participants responding to questions about BMI, diseases, and physical components of quality of life

\begin{tabular}{|c|c|c|c|}
\hline & Male $(n=2953)$ & Female $(n=2254)$ & Total $(n=5207)$ \\
\hline Age (mean) year & 42.94 & 42.67 & 42.38 \\
\hline \multicolumn{4}{|l|}{ Marital status } \\
\hline Married & $2240(75.8)^{*}$ & $1794(79.6)$ & $4034(77.5)$ \\
\hline Single & $699(23.7)$ & $326(14.5)$ & 1025 (19.7) \\
\hline Widowed & $9(0.3)$ & $118(5.2)$ & $127(2.4)$ \\
\hline divorced & $5(0.2)$ & $16(0.7)$ & $21(0.4)$ \\
\hline BMI $(\geq 25)$ & $1729(58.6)$ & $1733(76.9)$ & $3462(66.5)$ \\
\hline Having kidney inadequacy & $72(2.4)$ & $72(3.2)$ & $144(2.8)$ \\
\hline Having hypertension & $546(18.5)$ & $390(17.3)$ & $936(18.0)$ \\
\hline Having diabetes & $182(6.2)$ & $288(12.8)$ & $470(9.0)$ \\
\hline Having metabolic syndrome & $500(16.9)$ & 809 (35.9) & $1309(25.1)$ \\
\hline Having digestive disorders & $390(13.2)$ & $401(17.8)$ & $791(15.2)$ \\
\hline \multicolumn{4}{|c|}{ Physical components of quality of life } \\
\hline Poor & $321(10.9)$ & $193(8.5)$ & $514(9.9)$ \\
\hline Moderate & $1162(39.3)$ & $833(37.0)$ & $1995(38.3)$ \\
\hline Good & $1470(49.8)$ & $1228(54.5)$ & $2698(51.8)$ \\
\hline
\end{tabular}

Table 2. Comparison of LCA models with different latent classes based on model selection statistics

\begin{tabular}{ccccccc}
\hline $\begin{array}{c}\text { Number of } \\
\text { latent class }\end{array}$ & $\begin{array}{c}\text { Number of parameters } \\
\text { estimated }\end{array}$ & $\mathrm{G}^{2}$ & $\mathrm{df}$ & $\mathrm{AIC}$ & $\mathrm{BIC}$ & $\begin{array}{c}\text { Maximum } \\
\text { log-likelihood }\end{array}$ \\
\hline 1 & 8 & 1721.09 & 183 & 1737.09 & 1789.55 & -18042.80 \\
2 & 17 & 296.03 & 174 & 330.03 & 441.51 & -17330.27 \\
3 & 26 & 232.06 & 165 & 284.06 & 454.56 & -17298.29 \\
4 & 35 & 178.66 & 156 & 248.66 & 478.18 & -17271.59 \\
5 & 44 & 159.01 & 147 & 247.01 & 535.55 & -17261.76 \\
6 & 53 & 141.24 & 138 & 247.24 & 594.80 & -17252.88 \\
7 & 62 & 125.45 & 129 & 249.45 & 656.03 & -17244.98 \\
8 & 71 & 111.04 & 120 & 253.04 & 718.64 & -17237.78 \\
9 & 80 & 98.51 & 111 & 258.51 & 783.13 & -17231.52 \\
10 & 89 & 90.33 & 102 & 268.33 & 851.97 & 0.65 \\
\end{tabular}


Table 3. The six latent classes model of co-occurrence of body mass index, diseases, and physical component of quality of life: A latent class analysis

\begin{tabular}{|c|c|c|c|c|c|c|}
\hline & \multicolumn{6}{|c|}{ Latent class } \\
\hline & $\mathrm{C} 1$ & $\mathrm{C} 2$ & $\mathrm{C} 3$ & $\mathrm{C} 4$ & $\mathrm{C} 5$ & $\mathrm{C} 6$ \\
\hline Latent class prevalence & $0.351^{1}$ & 0.328 & 0.227 & 0.064 & 0.022 & 0.007 \\
\hline \multicolumn{7}{|l|}{ Item-response probabilities } \\
\hline \multicolumn{7}{|c|}{$\operatorname{BMI}(\geq 25)$} \\
\hline No & $0.606^{2}$ & 0.260 & 0.080 & 0.244 & 0.101 & 0.187 \\
\hline Yes & 0.394 & 0.740 & 0.920 & 0.756 & 0.898 & 0.813 \\
\hline \multicolumn{7}{|l|}{ Kidney inadequacy } \\
\hline No & 1.000 & 1.000 & 0.989 & 0.773 & 0.798 & 0.136 \\
\hline Yes & 0.000 & 0.000 & 0.111 & 0.227 & 0.202 & 0.864 \\
\hline \multicolumn{7}{|l|}{ Hypertension } \\
\hline No & 1.000 & 0.764 & 0.603 & 1.000 & 0.788 & 0.125 \\
\hline Yes & 0.000 & 0.236 & 0.397 & 0.000 & 0.212 & 0.875 \\
\hline \multicolumn{7}{|l|}{ Diabetes } \\
\hline No & 1.000 & 0.942 & 0.803 & 0.817 & 0.348 & 1.000 \\
\hline Yes & 0.000 & 0.058 & 0.196 & 0.182 & 0.652 & 0.000 \\
\hline \multicolumn{7}{|l|}{ Metabolic syndrome } \\
\hline No & 0.986 & 0.998 & 0.026 & 0.998 & 0.049 & 0.606 \\
\hline Yes & 0.014 & 0.002 & 0.973 & 0.002 & 0.951 & 0.394 \\
\hline \multicolumn{7}{|l|}{ Digestive disease } \\
\hline No & 0.902 & 0.872 & 0.843 & 0.656 & 0.303 & 0.648 \\
\hline Yes & 0.098 & 0.128 & 0.157 & 0.342 & 0.697 & 0.352 \\
\hline \multicolumn{7}{|c|}{ Physical components of quality of life } \\
\hline Poor & 0.087 & 0.108 & 0.098 & 0.111 & 0.088 & 0.155 \\
\hline Moderate & 0.458 & 0.316 & 0.377 & 0.300 & 0.431 & 0.581 \\
\hline Good & 0.454 & 0.576 & 0.524 & 0.592 & 0.480 & 0.264 \\
\hline
\end{tabular}

Note. The probability of a "No" response can be calculated by subtracting the item-response probabilities shown above from 1.

${ }^{1}$ The probability of being in each class

${ }^{2}$ Item-response probabilities $>0.5$ in bold to facilitate interpretation.

\section{Discussion}

In this study, we used latent class model to find patterns of some non-communicable diseases and physical component of quality of life.

Previous reports and researches showed a higher prevalence rate of BMI $(\geq 25)$, diabetes, and metabolic syndrome in Iranian women compared to men. Our findings confirm them. According to World Health Organization (WHO) report in the recent years, $48.5 \%$ of Iranian female adults were overweight $(\mathrm{BMI} \geq 25)$ and $19.2 \%$ were obese $(\mathrm{BMI} \geq 30)$. In contrast, overweight and obesity prevalence rate in men were $37 \%$ and $9.1 \%$, respectively (20). WHO diabetes's report indicated that prevalence of diabetes was $11.1 \%$ in Iranian women versus $9.6 \%$ in Iranian men (21). Moreover, in a meta-analysis it was concluded that diabetes risk in Iranian women is greater than in men (22). A great number of studies stated that the metabolic syndrome prevalence rate of Iranian women was significantly higher than Iranian men (23-25). So, it seems that women are considered as at-risk group in Iran.

More participants were in the first and second classes (nearly 68\%), and the third class had the most individuals with $22 \%$. The third latent class can be named metabolic syndrome and BMI $(\geq 25)$ class because there was a highest probability of having metabolic syndrome (97\% probability) and high BMI ( $\geq 25)$ (92\% probability) in this class. In the first class, individuals were free from any disease, but they did not proportionality have good physical components of quality of life status compared to other classes. Moreover, based on good physical components of quality of life status in the third class, being overweight and having metabolic syndrome did not impact quality of life. However, in latent class 5 , we found that by adding diabetes and digestive diseases to metabolic syndrome and
BMI $\geq 25$, the quality of life declined. In a longitudinal study on patients starting dialysis therapy, it was found that patients with diabetes had poorer physical component summary scores compared to non-diabetic patients (26). According to another study, higher BMI in patients with Type 2 diabetes was associated with poorer quality of life (27). Choi et al found that impairments of all domains of quality of life are due to functional gastrointestinal disorders (28). In the sixth class, having BMI $(\geq 25)$ cooccurred with kidney inadequacy, hypertension, and moderate physical component of quality of life status. Findings of the sixth class is consistent with Kalantar-Zadeh et al's study, who demonstrated the association of being overweight and a decline in physical health (dimension of quality of life) among patients on hemodialysis (29). Furthermore, latent classes 5 and 6 seem to be high risk classes and NCDs co-occurrences in these 2 classes may result in negative impacts on physical components of quality of life status.

All classes (except the first class) were characterized by BMI ( $\geq 25$ ), thus, there was co-occurrence among BMI $\geq 25$ and kidney inadequacy, hypertension, metabolic syndrome, diabetes, and digestive diseases. According to WHO report, obesity can increase the likelihood of diabetes, hypertension, coronary heart disease, stroke, and other chronic diseases (30). Several studies have focused on patterns of obesity. For example, Vistisen et al (2014) used latent class trajectory analysis in a cohort study. They indicated that the third group (persistently obese) had higher diabetes risk (31). Fitzpatrick et al (2013) showed 3 metabolic syndrome risk groups in adolescents and the high risk individuals were centrally obese (32).

Co-occurring separate conditions can lead to important opportunities for research (33). Most existing studies have 
focused on single factors or single diseases, so it seems that studies do not pay sufficient attention to the cooccurrence of NCDs (34). The strength of this study was utility of the latent class model to estimate co-occurrence of NCDs. This study had some limitations. It is of importance to pay attention to impacts of demographic variables and estimate their relations to latent classes. Moreover, the association between clinical examinations and laboratory values of each disease and latent classes should be determined. Finally, metabolic syndrome has different definitions and it may impact co-occurring findings of studies.

\section{Conclusion}

This study showed the pattern of body mass index, chronic diseases, and physical component of quality of life. Results revealed that most of the study participants fell into first and second classes. These results point out the critical importance of designing specific preventive interventional programs for these stratums of people.

Our findings revealed that some risk factors and noncommunicable diseases tend to accumulate in latent classes 3 to 6 , and thus the risk of developing these diseases rises with an increase in their clustering abilities. In the sixth class, along with high probability of having high BMI, kidney inadequacy and high hypertension, the moderate category of quality of life has high probability, indicating that with accumulation of more chronic diseases, it is expected that the quality of life reduce to poor level.

The results of this study could be useful to policymakers to develop integrated preventive interventions by considering the overall pattern and co-occurrence of the abovementioned items. Thus, it seems necessary to pay attention to overweight and obesity risk factors in Iranian adults, especially in women. The utility of evidence based on cooccurrence can determine the coordinated patterns of health conditions. For instance, co-occurrence approach can address effective integrated interventions (34). The results of this study may be useful to government policymakers to help them develop integrated preventive interventions.

\section{Acknowledgments}

The authors gratefully acknowledge persons who willingly contributed to this study.

\section{Conflict of Interests}

The authors declare that they have no competing interests.

\section{References}

1. Omran AR. The epidemiologic transition: a theory of the epidemiology of population change. Milbank Memor Fund Quart. 1971;49(4):509-38.

2. Feinstein AR. The pre-therapeutic classification of co-morbidity in chronic disease. J Chron Dis. 1970;23(7):455-68.

3. Kuwornu J, Lix L, Shooshtari S. Multimorbidity disease clusters in Aboriginal and non-Aboriginal Caucasian populations in Canada. Chronic Dis Injur Canada. 2014;34(4).
4. Valderas JM, Starfield B, Sibbald B, Salisbury C, Roland M. Defining comorbidity: implications for understanding health and health services. Ann Fam Med. 2009;7(4):357-63.

5. Menotti A, Mulder I, Nissinen A, Giampaoli S, Feskens EJ, Kromhout D. Prevalence of morbidity and multimorbidity in elderly male populations and their impact on 10-year all-cause mortality: The FINE study (Finland, Italy, Netherlands, Elderly). J Clin Epidemiol. 2001;54(7):680-6.

6. Loza E, Jover JA, Rodriguez L, Carmona L, Group ES, editors. Multimorbidity: prevalence, effect on quality of life and daily functioning, and variation of this effect when one condition is a rheumatic disease. Seminars in arthritis and rheumatism; 2009: Elsevier.

7. Tucker-Seeley RD, Li Y, Sorensen G, Subramanian S. Lifecourse socioeconomic circumstances and multimorbidity among older adults. BMC Pub Health. 2011;11(1):1.

8. Mathur R, Hull SA, Badrick E, Robson J. Cardiovascular multimorbidity: the effect of ethnicity on prevalence and risk factor management. Br J Gen Pract. 2011;61(586):e262-e70.

9. Orueta JF, Nuño-Solinís R, García-Alvarez A, Alonso-Morán E. Prevalence of multimorbidity according to the deprivation level among the elderly in the Basque Country. BMC Public Health. 2013;13(1):1.

10. Salive ME. Multimorbidity in older adults. Epidemiologic reviews. 2013:mxs009.

11. Dominick CH, Blyth FM, Nicholas MK. Unpacking the burden: understanding the relationships between chronic pain and comorbidity in the general population. Pain. 2012;153(2):293-304.

12. Brettschneider $\mathrm{C}$, Leicht $\mathrm{H}$, Bickel H, Dahlhaus A, Fuchs A, Gensichen J, et al. Relative impact of multimorbid chronic conditions on health-related quality of life-results from the MultiCare Cohort Study. PLoS One. 2013;8(6):e66742.

13. Baumeister H, Hutter N, Bengel J, Härter M. Quality of life in medically ill persons with comorbid mental disorders: a systematic review and meta-analysis. Psychother Psychosomat. 2011;80(5):27586.

14. Barile JP. Multiple chronic medical conditions and health-related quality of life in older adults, 2004-2006. Prev Chron Dis. 2013;10.

15. Leventhal AM, Huh J, Dunton GF. Clustering of modifiable biobehavioral risk factors for chronic disease in US adults: a latent class analysis. Perspect Pub Health. 2013:1757913913495780.

16. Smith SM, Soubhi H, Fortin M, Hudon C, O'Dowd T. Interventions for improving outcomes in patients with multimorbidity in primary care and community settings. Cochrane Library. 2012.

17. Cella D, Riley W, Stone A, Rothrock N, Reeve B, Yount S, et al. The Patient-Reported Outcomes Measurement Information System (PROMIS) developed and tested its first wave of adult self-reported health outcome item banks: 2005-2008. J Clin Epidemiol. 2010;63(11):1179-94.

18. Hays RD, Bjorner JB, Revicki DA, Spritzer KL, Cella D. Development of physical and mental health summary scores from the patient-reported outcomes measurement information system (PROMIS) global items. Qual Life Res. 2009;18(7):873-80.

19. Moriarty DG, Kobau R, Zack MM, Zahran HS. Tracking healthy days - a window on the health of older adults. Prev Chron Dis. 2005;2(3):A16.

20. The WHO Global Database on Body Mass Index [Internet]. 2016. Available from: http://www.who.int/bmi/index.jsp.

21. WHO. Diabetes country profiles 2016. Available from: http://www.who.int/diabetes/country-profiles/irn_en.pdf.

22. Haghdoost A, Rezazadeh-Kermani M, Sadghirad B, Baradaran H. Prevalence of type 2 diabetes in the Islamic Republic of Iran: systematic review and meta-analysis. East Mediterr Health J. 2009;15(3):591-9.

23. Maleki F, Sayehmiri F, Kiani F, Nasiri S. Metabolic syndrome prevalence in Iran: a systematic review and meta-analysis. J Kermanshah Univ Med Sci. 2014;18(4):242-50.

24. Azimi-Nezhad M, Herbeth B, Siest G, Dadé S, Ndiaye NC, Esmaily $\mathrm{H}$, et al. High prevalence of metabolic syndrome in Iran in comparison with France: what are the components that explain this? Metabol Syndr Relat Disord. 2012;10(3):181-8.

25. Shahbazian H, Latifi SM, Jalali MT, Shahbazian H, Amani R, Nikhoo A, et al. Metabolic syndrome and its correlated factors in an urban population in South West of Iran. J diabetes Metabol Disord. 2013;12(1):1. 
26. Martinez-Castelao A, Górriz JL, Garcia-Lopez F, Lopez-Revuelta K, De Alvaro F, Cruzado J. Perceived health-related quality of life and comorbidity in diabetic patients starting dialysis (CALVIDIA study). $\mathrm{J}$ Nephrol. 2004; 17:544-51.

27. Chyun DA, Melkus GD, Katten DM, Price WJ, Davey JA, Grey N, et al. The association of psychological factors, physical activity, neuropathy, and quality of life in type 2 diabetes. Biol Res Nurs. 2006;7(4):279-88.

28. Choi MG, Jung HK. Health related quality of life in functional gastrointestinal disorders in Asia. J Neurogastroenterol Motil. 2011;17(3):245..

29. Kalantar-Zadeh K, Kopple JD, Block G, Humphreys MH. Association among SF36 quality of life measures and nutrition, hospitalization, and mortality in hemodialysis. J Am Soc Nephrol. 2001;12(12):2797-806.

30. WHO. Global status report on noncommunicable diseases 2014 . Available from: http://apps.who.int/iris/bitstream/10665/148114/1/ 9789241564854_eng.pdf.

31. Vistisen D, Witte DR, Tabák AG, Herder C, Brunner EJ, Kivimäki $\mathrm{M}$, et al. Patterns of obesity development before the diagnosis of type 2 diabetes: the Whitehall II cohort study. PLoS Med. 2014;11(2):e1001602.

32. Fitzpatrick SL, Lai BS, Brancati FL, Golden SH, Hill-Briggs F. Metabolic Syndrome Risk Profiles Among African American Adolescents National Health and Nutrition Examination Survey, 2003-2010. Diabetes Care. 2013;36(2):436-42.

33. Rutter M. Comorbidity: Meanings and mechanisms. Clin Psychol: Sci Pract. 1994;1(1):100-3.

34. Haregu TN, Oti S, Egondi T, Kyobutungi C. Co-occurrence of behavioral risk factors of common non-communicable diseases among urban slum dwellers in Nairobi, Kenya. Global Health Action. 2015;8. 